\title{
Lifestyle and Sporadic Colorectal Cancer in India
}

\author{
Rupal Sinha ${ }^{1,3,5}$, Dinesh Chandra Doval ${ }^{2 *}$, Showket Hussain ${ }^{3}$, Kapil Kumar ${ }^{4}$, \\ Shivendra Singh ${ }^{4}$, Seemi Farhat Basir ${ }^{5}$, Mausumi Bharadwaj ${ }^{3 *}$
}

\begin{abstract}
Background: The study evaluated the patient, lifestyle and tumor profile in patients undergoing upfront surgery for sporadic colorectal cancer (CRC) in Indian population. Materials and Methods: One hundred consecutive patients were included. Details related to their demographic profile, habits, signs and symptoms, tumor profile, further treatment and follow up were recorded. Results: The majority of the patients had colonic cancer $(68 \%)$, advanced tumor stage $3 \& 4(46 \%)$, moderately differentiated tumors $(70 \%)$ with absence of lymphatic invasion $(60 \%)$ and metastasis $(90 \%)$. Correlations between tumor location and abdominal pain (p-value 0.002), bleeding per rectum (p-value $<0.001$ ), difficulty in micturition (p-value 0.012 ) and constipation (p-value 0.007) were found to be statistically significant. Abdominal pain was more frequently reported in patients with metastasis (p-value 0.031 ). Loss of weight statistically correlated with absence of lymphatic invasion (p-value $0.047)$. Associations between tumor stage and alcohol intake ( $p$-value 0.050 ) and non vegetarian diet (p-value 0.006); lymphatic invasion and intake of spicy food (p-value 0.040$)$ and non vegetarian diet (p-value 0.001 ) and metastasis and alcohol intake ( $p$-value 0.041 ) were also observed. Age and tumor grade were also correlated (p-value 0.020). Conclusions: Minimizing the adverse lifestyle factors can help in reducing the overall incidence of CRC in the Indian population.
\end{abstract}

Keywords: Signs and symptoms - tumor profile - lifestyle factors - sporadic colorectal cancer

Asian Pac J Cancer Prev, 16 (17), 7683-7688

\section{Introduction}

Colorectal cancer (CRC) is the third commonest cancer worldwide and designated as the leading cause of cancer deaths with incidence rates about 2 to 5 times higher in the developed countries in comparison to the developing countries (Notani PN, 2001). In India, the estimated incidence and mortality from CRC is 36476 cases and 25690 cases, respectively (Ferlay et al., 2010). It is a heterogeneous disease with complex etiology and its pathogenesis may be attributed to a variety of predisposing factors including physical inactivity, overweight and obesity, red and processed meat consumption, smoking and excessive alcohol consumption (Notani PN, 2001). These attributable factors may either singly or in combination synergistically may help in the rapid progression and multistep development of this disease. Different set of patients may present with variable symptoms depending upon the nature and aggressiveness of the disease. Delay in the presentation of symptoms remains a critical challenge in the early and timely diagnosis of CRC (MacArthur et al., 1984).

Genetic and epigenetic influences have also been shown to affect the disease progression in CRC and a host of genes may act synergistically and transform the epithelial cells into adenocarcinomas (Sinha et al., 2013). Patients need to be managed differently depending upon a range of factors including the tumor profile, general physical condition, performance status, etc. Numerous studies have found the risk factors to be more evident and significantly associated in men (Giovannucci et al., 1994). Also, age wise classification of patients in terms of the risk factors may help in categorizing whether the younger or elderly patients are more affected with the disease and strengthening the approach towards managing this disease.

Identifying the risk factors associated with the causation and subsequent development of the disease may help in gaining a better understanding of the disease to assist in screening and assessing the prognosis of the patients suffering with this diverse group of cancers. The present study was thus aimed to evaluate the patient, lifestyle and tumor profile of patients undergoing upfront surgery for sporadic CRC in Indian population.

\section{Materials and Methods}

A total of 100 consecutive patients who underwent upfront surgery for sporadic CRC in the Department of Surgical Oncology at Rajiv Gandhi Cancer Institute and Research Centre, Delhi, India were included in the study.

${ }^{1}$ Department of Research, ${ }^{2}$ Department of Medical Oncology, ${ }^{4}$ Department of Surgical Oncology, Rajiv Gandhi Cancer Institute \& Research Centre, Delhi, ${ }^{3}$ Division of Molecular Genetics \& Biochemistry, Institute of Cytology \& Preventive Oncology (ICMR), Noida, Uttar Pradesh, ${ }^{5}$ Department of Biosciences, Jamia Millia Islamia, New Delhi, India*For correspondence: mausumi02@ yahoo.com,bharadwajm@icmr.org.in,dcdoval@gmail.com 
None of these patients had received any pre-operative treatment in the form of radiation or chemotherapy. Histopathological grades and clinical staging were evaluated according to the standard criteria (Edge et al., 2010) by two independent pathologists. Only histopathologically confirmed cases were included in this study. Details of each patient related to their demographic profile, habits, signs and symptoms, personal history, tumor profile including metastasis and histopathology reports, further treatment and follow up information was also recorded. The study was granted waiver by the Institutional Review Board and has been performed in accordance with the ethical standards laid down in the 1964 Declaration of Helsinki and its later amendments.

\section{Statistical analysis}

All statistical analyses were performed by the standard methods using IBM SPSS Statistics (Version 22, IBM Corp, USA). Fischer's Exact Test or Chi Square Test was used as applicable. The findings were considered statistically significant at $\mathrm{p}$ values of $<0.05$. Overall survival (OS) was calculated by the Kaplan Meier survival method (Kaplan and Meier, 1958).

\section{Results}

A total of 100 patients with sporadic CRC were included in the study. The mean age at diagnosis of these patients was 52 years with a higher preponderance of male patients $(77 \%)$. Altogether, $26 \%$ patients had presented with co-morbidities including hypertension, diabetes, heart disease and tuberculosis. Also, 12\% patients had a family history of cancer. The details of demographic profile and follow up information is given in Table 1 . Computed tomography scan performed in $77 \%$ patients was the most common mode of diagnosis. Post surgery, chemotherapy was administered in $39 \%$ patients. The overall survival of these cases was $99 \%$ at 49 months while the median follow up was 8.5 months.

Majority of the patients had colonic cancer (68/100), advanced tumor stage 3 and 4 (46/100), moderately differentiated tumors (70/100) with absence of lymphatic invasion (60/100) and metastasis (90/100). The correlation between signs and symptoms and the tumor profile of the patients is shown in Table 2. The most commonly observed signs and symptoms included abdominal pain $(58 \%)$ and loss of weight (53\%) followed by bleeding per rectum $(48 \%)$. Abdominal pain was seen more frequently in colonic tumors $(69.1 \%)$ and stage 4 disease $(80 \%)$ with undifferentiated tumor $(100 \%)$, presence of lymphatic invasion $(60 \%)$ and metastasis $(90 \%)$. Loss of weight was more commonly observed in rectosigmoid tumors $(70 \%)$ and stage 4 disease $(80 \%)$ with undifferentiated tissue $(100 \%)$, presence of lymphatic invasion (55\%) and metastasis $(60 \%)$. Bleeding per rectum was predominant in rectal tumors $(86.4 \%)$ and stage 4 disease $(60 \%)$ with undifferentiated tissue $(100 \%)$ and presence of lymphatic invasion (57.5\%) and absence of metastasis (48.9\%). The correlation between tumor location and abdominal pain (p-value 0.002), bleeding per rectum ( $\mathrm{p}$-value $<0.001$ ), difficulty in micturition (p-value 0.012 ) and constipation (p-value 0.007) was found to be statistically significant. Also, abdominal pain was more frequently reported in patients with metastasis (p-value 0.031 ). Loss of weight statistically correlated with the absence of lymphatic invasion ( $\mathrm{p}$-value 0.047 )

The correlation between lifestyle factors and the tumor profile of the patients is given in Table 3. Among the lifestyle factors, intake of fatty food $(60 \%)$, spicy food $(45 \%)$ and non vegetarian diet $(43 \%)$ were more frequently witnessed. Intake of fatty food was more commonly observed in colonic tumors $(67.6 \%)$ and stage 3 disease $(63.4 \%)$ with undifferentiated tissue (100\%) and presence of lymphatic invasion $(62.5 \%)$. Spicy food intake was more frequent in patients with colonic tumors $(48.5 \%)$, stage 3 disease $(61 \%)$ with undifferentiated tissue $(100 \%)$, presence of lymphatic invasion $(57.5 \%)$ and presence of metastasis $(50 \%)$. Non vegetarian diet was associated with rectosigmoid tumors (50\%) and

Table 1. Demographic profile and follow up of $\mathbf{1 0 0}$ patients with sporadic CRC

\begin{tabular}{|c|c|}
\hline Characteristic & $\mathrm{N}(\%)$ \\
\hline Mean age at diagnosis & $52.6+14.2$ years \\
\hline Males : Females & $77(77 \%): 23(23 \%)$ \\
\hline Co morbidities* & $26(26 \%)$ \\
\hline Family history of cancer & $12(12 \%)$ \\
\hline \multicolumn{2}{|l|}{ Signs \& Symptoms } \\
\hline Abdominal pain & $58(58 \%)$ \\
\hline Loss of weight & $53(53 \%)$ \\
\hline Bleeding per rectum & $48(48 \%)$ \\
\hline Fatigue & $44(44 \%)$ \\
\hline Constipation & $43(43 \%)$ \\
\hline Loss of appetite & $42(42 \%)$ \\
\hline Obstruction features & $29(29 \%)$ \\
\hline Back pain & $22(22 \%)$ \\
\hline Diarrhea & $21(21 \%)$ \\
\hline Nausea \& Vomiting & $13(13 \%)$ \\
\hline Difficulty in micturition & $8(8 \%)$ \\
\hline \multicolumn{2}{|l|}{ Lifestyle factors } \\
\hline Fatty diet & $60(60 \%)$ \\
\hline Spicy food & $45(45 \%)$ \\
\hline Non-vegetarian diet & $43(43 \%)$ \\
\hline Alcohol intake & $40(40 \%)$ \\
\hline Smoking & $39(39 \%)$ \\
\hline Irregular intake of fruits & $27(27 \%)$ \\
\hline Lack of physical exercise & $25(25 \%)$ \\
\hline Tobacco chewing & $15(15 \%)$ \\
\hline \multicolumn{2}{|l|}{ Mode of diagnosis } \\
\hline Computed tomography scan & $77(77 \%)$ \\
\hline Biopsy & $57(57 \%)$ \\
\hline Colonoscopy & $52(52 \%)$ \\
\hline \multicolumn{2}{|l|}{ Treatment received } \\
\hline Surgery only & $50(50 \%)$ \\
\hline Surgery $+\mathrm{CT}^{* *}$ only & $39(39 \%)$ \\
\hline Surgery $+\mathrm{RT}^{* *}$ only & $2(2 \%)$ \\
\hline Surgery $+\mathrm{CT}^{* *}+\mathrm{RT}^{* *}$ & $9(9 \%)$ \\
\hline \multicolumn{2}{|l|}{ Follow up } \\
\hline Overall survival & $99 \%$ at 49 months \\
\hline Status - Dead & $1(1 \%)$ \\
\hline Median follow up & $\begin{array}{r}8.5 \text { months } \\
\text { (1-49 months) }\end{array}$ \\
\hline
\end{tabular}

* Co morbidities include hypertension, diabetes, heart diseases and tuberculosis; ** CT, chemotherapy; RT, radiotherapy: both given adjuvantly 
stage 4 disease $(80 \%)$ with poorly differentiated tissue $(56.5 \%)$ and presence of lymphatic invasion $(62.5 \%)$ and metastasis $(70 \%)$. The correlation between tumor stage and alcohol intake ( $\mathrm{p}$-value 0.050 ) and non vegetarian diet (p-value 0.006); lymphatic invasion and intake of spicy food (p-value 0.040) and non vegetarian diet ( $\mathrm{p}$-value

Table 2. Correlation between Signs \& Symptoms and tumor profile of 100 patients with sporadic CRC

\begin{tabular}{|c|c|c|c|c|c|c|c|c|c|c|c|c|}
\hline Char & $\mathrm{N}$ & $\begin{array}{l}\text { Loss of } \\
\text { weight } \\
\text { n (\%) }\end{array}$ & $\begin{array}{l}\text { Vomiting } \\
\text { n (\%) }\end{array}$ & $\begin{array}{l}\text { Abdominal } \\
\text { pain } \\
\mathrm{n}(\%)\end{array}$ & Diarrhea & $\begin{array}{l}\text { Bleeding D } \\
\text { per rectum } \\
\text { n }(\%)\end{array}$ & $\begin{array}{l}\text { ifficulty in } \\
\text { micturition } \\
\mathrm{n}(\%)\end{array}$ & & & $\begin{array}{l}\text { Obstruction } \\
\text { features } \\
\mathrm{n}(\%)\end{array}$ & $\begin{array}{l}\text { Loss of } \\
\text { appetite } \\
\text { n }(\%)\end{array}$ & Back pain \\
\hline \multicolumn{13}{|l|}{ Tumor location } \\
\hline Colon & 68 & $37(54.4)$ & $11(16.2)$ & $47(69.1)$ & $15(22.1)$ & $22(32.4)$ & $2(2.9)$ & $22(32.4)$ & $33(48.5)$ & $16(23.5)$ & $34(50)$ & $14(20.6)$ \\
\hline Rectum & 22 & $9(40.9)$ & $2(9.1)$ & $6(27.3)$ & $5(22.7)$ & $19(86.4)$ & $5(22.7)$ & $15(68.2)$ & $9(40.9)$ & $10(45.5)$ & $5(22.7)$ & $6(27.3)$ \\
\hline Rectosigmoid & 10 & $7(70)$ & $0(0)$ & $5(50)$ & $1(10)$ & $7(70)$ & $1(10)$ & $6(60)$ & $2(20)$ & $3(30)$ & $3(10)$ & $2(20)$ \\
\hline p-value & & 0.286 & 0.301 & 0.002 & 0.665 & $<0.001$ & 0.012 & 0.007 & 0.224 & 0.143 & 0.057 & 0.795 \\
\hline \multicolumn{13}{|l|}{ Tumor stage } \\
\hline 1 & 11 & $6(54.5)$ & $0(0)$ & $3(27.3)$ & $5(45.5)$ & $5(45.5)$ & $0(0)$ & $5(45.5)$ & $5(45.5)$ & $4(36.4)$ & $3(27.3)$ & $3(27.3)$ \\
\hline 2 & 43 & $21(48.8)$ & 5 (11.6) & $27(62.8)$ & 5 (11.6) & $20(46.5)$ & $4(9.3)$ & 15 (34.9) & $19(44.2)$ & $11(25.6)$ & $23(53.5)$ & $9(20.9)$ \\
\hline 3 & 41 & $22(53.7)$ & $7(17.1)$ & $24(58.5)$ & $10(24.4)$ & $20(48.8)$ & $3(7.3)$ & $20(48.8)$ & $17(41.5)$ & $11(26.8)$ & $14(34.1)$ & $8(19.5)$ \\
\hline 4 & 5 & $4(80)$ & $1(20)$ & $4(80)$ & $1(20)$ & $3(60)$ & $1(20)$ & $3(60)$ & $3(60)$ & $3(60)$ & $2(40)$ & $2(40)$ \\
\hline $\mathrm{p}$-value & & 0.619 & 0.469 & 0.129 & 0.089 & 0.947 & 0.56 & 0.507 & 0.888 & 0.398 & 0.226 & 0.729 \\
\hline \multicolumn{13}{|l|}{ Tumor grade* } \\
\hline WD & 6 & $4(66.7)$ & $1(16.7)$ & $3(50)$ & $2(33.3)$ & $3(50)$ & $0(0)$ & $1(16.7)$ & $2(33.3)$ & $2(33.3)$ & $4(66.7)$ & $1(16.7)$ \\
\hline MD & 70 & $33(47.1)$ & $11(15.7)$ & $42(60)$ & $11(15.7)$ & $34(48.6)$ & $7(10)$ & $36(51.4)$ & $29(41.4)$ & $20(28.6)$ & $28(40)$ & $15(21.4)$ \\
\hline PD & 23 & $15(65.2)$ & $1(4.3)$ & $12(52.2)$ & $8(34.8)$ & $10(43.5)$ & $1(4.3)$ & $6(26.1)$ & $12(52.2)$ & $7(30.4)$ & $10(43.5)$ & $5(21.7)$ \\
\hline $\mathrm{U}$ & 1 & $1(100)$ & $0(0)$ & $1(100)$ & $0(0)$ & $1(100)$ & $0(0)$ & $0(0)$ & $1(100)$ & $0(0)$ & $0(0)$ & $1(100)$ \\
\hline p-value & & 0.298 & 0.532 & 0.725 & 0.201 & 0.731 & 0.704 & 0.067 & 0.501 & 0.921 & 0.501 & 0.301 \\
\hline \multicolumn{13}{|c|}{ Lymphatic invasion } \\
\hline Absent & 60 & $31(51.7)$ & $8(13.3)$ & $34(56.7)$ & $11(18.3)$ & $25(41.7)$ & $3(5)$ & $22(36.7)$ & $26(43.3)$ & $16(26.7)$ & $30(50)$ & $13(21.7)$ \\
\hline Present & 40 & $22(55)$ & $5(12.5)$ & $24(60)$ & $10(25)$ & $23(57.5)$ & $5(12.5)$ & $21(52.5)$ & $18(45)$ & $13(32.5)$ & $12(30)$ & $12(30)$ \\
\hline $\mathrm{p}$-value & & 0.744 & 0.903 & 0.741 & 0.423 & 0.121 & 0.176 & 0.117 & 0.869 & 0.529 & 0.047 & 0.921 \\
\hline \multicolumn{13}{|l|}{ Metastasis } \\
\hline Absent & 90 & $47(52.2)$ & $10(11.1)$ & $49(54.4)$ & $19(21.1)$ & $44(48.9)$ & $7(7.8)$ & $39(43.3)$ & $38(42.2)$ & $26(28.9)$ & $39(43.3)$ & $18(20)$ \\
\hline Present & 10 & $6(60)$ & $3(30)$ & $9(90)$ & $2(20)$ & $4(40)$ & $1(10)$ & $4(40)$ & $6(60)$ & $3(30)$ & $3(30)$ & $4(40)$ \\
\hline $\mathrm{p}$-value & & 0.64 & 0.092 & 0.031 & 0.935 & 0.594 & 0.806 & 0.84 & 0.283 & 0.941 & 0.418 & 0.148 \\
\hline
\end{tabular}

*WD, well differentiated; $\mathrm{MD}$, moderately differentiated; $\mathrm{PD}$, poorly differentiated; $\mathrm{U}$, undifferentiated; $\mathrm{p}$ value $<0.05$ was taken as significant

Table 3. Correlation between lifestyle factors and tumor profile of 100 patients with sporadic CRC

\begin{tabular}{|c|c|c|c|c|c|c|c|c|c|}
\hline Characteristic & $\mathrm{N}$ & $\begin{array}{c}\text { Alcohol } \\
\text { intake } \\
\text { n }(\%)\end{array}$ & $\begin{array}{c}\text { Tobacco } \\
\text { chewing } \\
\mathrm{n}(\%)\end{array}$ & Smoking & $\begin{array}{c}\begin{array}{c}\text { Fatty } \\
\text { diet }\end{array} \\
\text { n }(\%)\end{array}$ & $\begin{array}{l}\text { Irregular } \\
\text { intake } \\
\text { of fruits } \\
n(\%)\end{array}$ & $\begin{array}{l}\text { Spicy } \\
\text { food } \\
\mathrm{n}(\%)\end{array}$ & $\begin{array}{c}\text { Non } \\
\text { vegetarian } \\
\text { diet } \\
\text { n }(\%)\end{array}$ & $\begin{array}{c}\text { Lack of } \\
\text { physical } \\
\text { exercise } \\
\text { n (\%) }\end{array}$ \\
\hline \multicolumn{10}{|l|}{ Tumor location } \\
\hline Colon & 68 & $30(44.1)$ & $10(14.7)$ & $28(41.2)$ & $46(67.6)$ & $14(20.6)$ & $33(48.5)$ & $31(45.6)$ & $13(19.1)$ \\
\hline Rectum & 22 & $6(27.3)$ & $3(13.6)$ & $8(36.4)$ & $10(45.5)$ & $8(36.4)$ & $8(36.4)$ & 7 (31.8) & $8(36.4)$ \\
\hline Rectosigmoid & 10 & $4(40)$ & $2(20)$ & $3(30)$ & $4(40)$ & $5(50)$ & $4(40)$ & $5(50)$ & $4(40)$ \\
\hline p-value & & 0.374 & 0.89 & 0.763 & 0.072 & 0.079 & 0.575 & 0.471 & 0.137 \\
\hline \multicolumn{10}{|l|}{ Tumor stage } \\
\hline 1 & 11 & $1(9.1)$ & $1(9.1)$ & $2(18.2)$ & $5(45.5)$ & $4(36.4)$ & $4(36.4)$ & $2(18.2)$ & $5(45.5)$ \\
\hline 2 & 43 & $18(41.9)$ & $7(16.3)$ & $14(32.6)$ & $27(62.8)$ & $11(25.6)$ & $14(32.6)$ & $13(30.2)$ & $6(14)$ \\
\hline 3 & 41 & $17(41.5)$ & $7(17.1)$ & 19 (46.3) & $26(63.4)$ & $12(29.3)$ & $25(61)$ & $24(58.5)$ & $13(31.7)$ \\
\hline 4 & 5 & $4(80)$ & $0(0)$ & $4(80)$ & $2(40)$ & $0(0)$ & $2(40)$ & $4(80)$ & $1(20)$ \\
\hline $\mathrm{p}$-value & & 0.05 & 0.711 & 0.065 & 0.544 & 0.477 & 0.063 & 0.006 & 0.098 \\
\hline \multicolumn{10}{|l|}{ Tumor grade* } \\
\hline WD & 6 & $4(66.7)$ & $1(16.7)$ & $2(33.3)$ & $3(50)$ & $1(16.7)$ & $4(66.7)$ & $2(33.3)$ & $2(33.3)$ \\
\hline $\mathrm{MD}$ & 70 & 27 (38.6) & $10(70)$ & 29 (41.4) & $43(61.4)$ & $20(28.6)$ & $31(44.3)$ & $28(40)$ & $15(21.4)$ \\
\hline PD & 23 & $8(34.8)$ & $4(17.4)$ & $8(34.8)$ & $13(56.5)$ & $6(26.1)$ & $9(39.1)$ & $13(56.5)$ & $8(34.8)$ \\
\hline $\mathrm{U}$ & 1 & $1(100)$ & $0(0)$ & $0(0)$ & $1(100)$ & $0(0)$ & $1(100)$ & $0(0)$ & $0(0)$ \\
\hline p-value & & 0.308 & 0.956 & 0.785 & 0.779 & 0.851 & 0.441 & 0.398 & 0.531 \\
\hline \multicolumn{10}{|c|}{ Lymphatic invasion } \\
\hline Absent & 60 & $22(36.7)$ & $11(18.3)$ & $21(35)$ & $35(58.3)$ & $18(30)$ & $22(36.7)$ & $18(30)$ & $14(23.3)$ \\
\hline Present & 40 & $18(45)$ & $4(10)$ & $18(45)$ & $25(62.5)$ & $9(22.5)$ & $23(57.5)$ & $25(62.5)$ & $11(27.5)$ \\
\hline $\mathrm{p}$-value & & 0.405 & 0.253 & 0.315 & 0.677 & 0.408 & 0.04 & 0.001 & 0.637 \\
\hline \multicolumn{10}{|l|}{ Metastasis } \\
\hline Absent & 90 & $33(36.7)$ & $13(14.4)$ & $34(37.8)$ & $54(60)$ & $25(27.8)$ & $40(44.4)$ & $36(40)$ & $22(24.4)$ \\
\hline Present & 10 & $7(70)$ & $2(20)$ & $5(50)$ & $6(60)$ & $2(20)$ & $5(50)$ & $7(70)$ & $3(30)$ \\
\hline $\mathrm{p}$-value & & 0.041 & 0.641 & 0.452 & 1 & 0.599 & 0.738 & 0.069 & 0.7 \\
\hline
\end{tabular}

*WD, well differentiated; MD, moderately differentiated; $\mathrm{PD}$, poorly differentiated; $\mathrm{U}$, undifferentiated; $\mathrm{p}$ value $<0.05$ was taken as significant 
Table 4. Correlation between Age, Gender and Tumor Profile of 100 Patients with Sporadic CRC

\begin{tabular}{|c|c|c|c|c|c|c|c|}
\hline \multirow[t]{2}{*}{ Characteristic } & \multirow[t]{2}{*}{$\mathrm{N}$} & \multicolumn{3}{|c|}{ Age } & \multicolumn{3}{|c|}{ Gender } \\
\hline & & $\begin{array}{c}<30 \text { years } \\
\mathrm{n}(\%)\end{array}$ & $\begin{array}{c}>30 \text { years } \\
\mathrm{n}(\%)\end{array}$ & p-value & $\begin{array}{l}\text { Male } \\
\mathrm{n}(\%)\end{array}$ & $\begin{array}{c}\text { Female } \\
\mathrm{n}(\%)\end{array}$ & $\mathrm{p}$-value \\
\hline \multicolumn{8}{|l|}{ Tumor location } \\
\hline Colon & 68 & $5(7.4)$ & $63(92.6)$ & 0.176 & $54(79.4)$ & $14(20.6)$ & 0.395 \\
\hline Rectum & 22 & $4(18.2)$ & $18(81.8)$ & & $17(77.3)$ & $5(22.7)$ & \\
\hline Rectosigmoid & 10 & $0(0)$ & $10(100)$ & & $6(60)$ & $4(40)$ & \\
\hline \multicolumn{8}{|l|}{ Tumor stage } \\
\hline $1 \& 2$ & 54 & $4(7.4)$ & $50(92.6)$ & 0.547 & $41(75.9)$ & $13(24.1)$ & 0.863 \\
\hline $3 \& 4$ & 46 & $5(10.9)$ & $41(89.1)$ & & $36(78.3)$ & $10(21.7)$ & \\
\hline \multicolumn{8}{|l|}{ Tumor grade* } \\
\hline WD \& MD & 76 & $4(5.3)$ & $72(94.7)$ & 0.02 & $56(73.7)$ & $20(26.3)$ & 0.161 \\
\hline PD \& U & 24 & $5(20.8)$ & $19(79.2)$ & & $21(87.5)$ & $3(12.5)$ & \\
\hline \multicolumn{8}{|l|}{ Lymphatic invasion } \\
\hline Absent & 60 & $3(5)$ & $57(95)$ & 0.087 & $45(75)$ & $15(25)$ & 0.561 \\
\hline Present & 40 & $6(15)$ & $34(85)$ & & $32(80)$ & $8(20)$ & \\
\hline \multicolumn{8}{|l|}{ Metastasis } \\
\hline Absent & 90 & $8(8.9)$ & $82(91.1)$ & 0.907 & $69(76.7)$ & $21(23.3)$ & 0.812 \\
\hline Present & 10 & $1(10)$ & $9(90)$ & & $8(80)$ & $2(20)$ & \\
\hline
\end{tabular}

*WD, well differentiated; MD, moderately differentiated; PD, poorly differentiated; $\mathrm{U}$, undifferentiated; $\mathrm{p}$ value $<0.05$ was taken as significant

$0.001)$ and metastasis and alcohol intake (p-value 0.041) were found to be statistically significant.

Correlation between age and tumor profile is presented in Table 4. A total of 9 patients were in the age group of $<30$ years whereas 91 patients belonged to the age group of $>30$ years. The younger patients showed the presence of rectal tumors (18.2\%), stage 3 and 4 disease (10.9\%) with poorly differentiated and undifferentiated tumors $(20.8 \%)$, presence of lymphatic invasion (15\%) and metastasis $(10 \%)$. On the other hand, the older patients showed a preponderance of rectosigmoid tumors (100\%) and stage 1 and 2 disease (92.6\%) with well to moderately differentiated tumor $(94.7 \%)$, absence of lymphatic invasion (95\%) and absence of metastasis (91.1\%). Correlation between age and tumor grade was found to be statistically significant (p-value 0.020). Furthermore, majority of the male patients had colonic tumors $(79.4 \%)$, stage 3 and 4 disease $(78.3 \%)$, poorly and undifferentiated tumors $(87.5 \%)$, presence of lymphatic invasion $(80 \%)$ and presence of metastasis $(80 \%)$ whereas the female patients mostly had rectosigmoid tumors (40\%), stage 1 and 2 disease $(24.1 \%)$, well to moderately differentiated tumors $(26.3 \%)$, absence of lymphatic invasion $(25 \%)$ and metastasis $(23.3 \%)$.

\section{Discussion}

CRC is a multistep and multifactorial disease and an excellent example for gaining the deepest insights into the process of carcinogenesis (Lao and Grady, 2011; Hibi and Nakao, 2006). At the molecular level, studies have clearly shown that genetic/ epigenetic changes may greatly affect the development of the disease transforming the epithelial cells into adenocarcinomas (Frank et al., 2010; Carvalho et al., 2012; Sinha et al., 2013; Farkas et al., 2014). Numerous signs and symptoms have been reported in patients presenting with CRC and a host of attributable factors have been found to play a significant role in the development of this disease. Minimizing the adverse and unhealthy factors and adopting a healthier lifestyle can help in reducing the overall incidence of this disease. Further, if the symptoms are dealt with in a stricter fashion, it might greatly help in picking up the disease at an early stage. To the best of our knowledge, this is the first study to simultaneously explore the roles of various presenting symptoms and the lifestyle factors and their effect on the detailed profile of tumor in CRC patients undergoing upfront surgery for this disease in the Indian population.

Numerous studies have reported the common signs and symptoms observed in patients with CRC. In our study, it was observed that abdominal pain (58\%), loss of weight (53\%) and bleeding per rectum (48\%) were the most commonly reported signs and symptoms. Majumdar et al observed the most common symptoms of CRC to be rectal bleeding $(58 \%)$, abdominal pain $(52 \%)$ and change in bowel habits (51\%) (Majumdar et al., 1999). The authors clearly stated that the physicians should continue to rely on the clinical findings for detecting this cancer. Studies have reported the presence of rectal bleeding as a single symptom or it may also present in conjunction with other symptoms (Astin et al., 2011). Most of the symptoms present more rampantly in higher stage tumors as an indicator of the aggressive nature of this disease, however, this may not always be true. Often, the symptoms initially may not even be identifiable and often go undiagnosed. It may not be correlated with cancer per se and hence is confused with other medical conditions. These symptoms, especially if appearing in conjunction with others should be addressed with a more focused approach to rule out the possibilities of misinterpretation and to come down to the specific disease diagnosis for initiating treatment as soon as possible, given the gravity of this disease.

Environmental factors including lifestyle modifications rampant in various countries are important but modifiable predictors of the disease (Gingras et al., 2011; Jemal et al., 2011). Risk factors including red and processed meat consumption, obesity, physical inactivity, excessive 
smoking and alcohol consumption may significantly manipulate the causation of CRC (Giovannucci et al., 1995; Boyle et al., 2011; Jemal et al., 2011; Kim et al., 2011; Sinha et al., 2013). In our study, intake of fatty diet $(60 \%)$, spicy food $(45 \%)$ and non vegetarian diet $(43 \%)$ were the most commonly observed lifestyle factors. The lifestyle factors were found to greatly affect the disease and directly correlated with higher stage and tumor grade. Also, the presence of these factors was more commonly witnessed in tumors with presence of lymphatic invasion and metastasis highlighting the fact that all these factors contribute towards the development of more aggressive tumors. Identifying the early symptoms and the lifestyle factors may be greatly helpful in identifying the disease at an early treatable stage. Lifestyle in the Indian population is witnessing a dramatic shift towards that observed in the western population. Intake of fruits and vegetables which have increased amounts of salicyclic acid and shown to have an anticancer effect by sensitizing the normal cells to evade tumor formation is dramatically being replaced by ready to eat foods. Alcohol has also been observed to play a role in the development of CRC (Seitz et al., 1990). Alcohol may increase the risk for CRC indirectly through immune suppression, delay of DNA repair, activation of liver procarcinogens by induction of cytochrome P- 450 enzymes, or changes in bile acid composition (Kune et al., 1992). Risk of colon cancer was increased with high intake of red and processed meat chiefly due to the formation of heterocyclic aromatic amines due to high temperature cooking of meat proteins (Magalhaes et al., 2012). Increased risk of CRC has been observed upon cigarette smoking due to the carcinogenic action of polynuclear aromatic hydrocarbons, nitrosamines and aromatic amines, either present in, or produced by, burning tobacco (Giovannucci et al., 1996). By lifestyle modifications and adopting a healthier routine, the overall risk of developing disease including cancer can greatly be reduced thereby increasing the life span of most individuals.

$\mathrm{CRC}$ is a disease affecting the individuals in the later stages of their lives. Very few patients (approximately $1 \%$ of CRCs) present in the early stages of their lives (Recio and Bussey, 1965; Rodriguez-Bigas et al., 1996; Miller and Liechty, 1967). A total of $9 \%$ patients were in the age group $<30$ years in the present study and found to have higher stage (10.9\%) and higher grade (20.8\%) tumors with the presence of lymphatic invasion $(15 \%)$ and metastasis $(10 \%)$. Different studies have investigated the incidence rates and the underlying causes of the development of the disease in the younger patients (Recio and Bussey, 1965; Mills and Shannon Allen, 1979; Gardner et al., 1981; Elliot and Steven, 1984; Rao et al., 1985; Palmer et al., 1991; Cozart et al., 1993; McGaharen et al., 1995). CRC has been found to have a worse prognosis among the younger patients which may be due to the advanced stage of the tumor at the time of diagnosis of this disease. However, why these patients present with advanced tumors is a matter of grave concern and a futuristic area of research. In a study by Minardi et al, the younger patients presented with an increased incidence of advanced disease and $37 \%$ of the lesions were Duke's C and $22 \%$ were Duke's D (Minardi et al., 1998). Also, in the present study, the male patients showed a preponderance of higher stage $(78.3 \%)$ and higher grade $(87.5 \%)$ with the presence of lymphatic invasion (80\%) and metastasis $(80 \%)$.

Identifying the symptoms at an early stage and modifying the lifestyle factors may greatly help in reducing the overall burden of this disease. Also, it becomes absolutely imperative for the managing physician to have a more stringent approach towards this disease in the younger patients and male patients.

\section{Acknowledgements}

The authors would like to thank Rajiv Gandhi Cancer Institute and Research Centre, Delhi, India for providing the biological samples and clinical information and Institute of Cytology and Preventive Oncology (ICMR), Noida, Uttar Pradesh, India for providing the core infrastructural facilities.

\section{References}

Astin M, Griffin T, Neal RD, et al (2011). The diagnostic value of symptoms for colorectal cancer in primary care: a systematic review. Br J Gen Pract, 61, 231-43.

Boyle T, Fritschi L, Heyworth J, et al (2011). Long-term sedentary work and the risk of subsite-specific colorectal cancer. Am J Epidemiol, 173, 1183-91.

Carvalho B, Sillars-Hardebol AH, Postma C, et al (2012). Colorectal adenoma to carcinoma progression is accompanied by changes in gene expression associated with ageing, chromosomal instability, and fatty acid metabolism. Cell Oncol, 35, 53-63.

Cozart DT, Lang NP, Hauser-Jensen M (1993). Contributors to the southwestern surgical congress unusual case registry. colorectal cancer in patients under 30 years of age. Am J Surg, 166, 764-7.

Edge S, Byrd DR, Compton CC, et al (Eds.) (2010). Cancer staging handbook: from the AJCC cancer staging manual. Springer Publishing Company, 173-206.

Elliot MS, Steven DM (1984). Carcinoma of the colon and rectum in patients under 30 years of age. $S$ Afr Med J, 66, 129-31.

Farkas SA, Vymetalkova V, Vodickova L, et al (2014). DNA methylation changes in genes frequently mutated in sporadic colorectal cancer and in the DNA repair and $\mathrm{Wnt} / \beta$-catenin signaling pathway genes. Epigenomics, 6, 179-91.

Ferlay J, Shin HR, Bray F, et al (2010). Estimates of worldwide burden of cancer in 2008: GLOBOCAN 2008. Int J Cancer, 127, 2893-917.

Frank B, Hoffmeister M, Klopp N, et al (2010). Polymorphisms in inflammatory pathway genes and their association with colorectal cancer risk. Int J Cancer, 127, 2822-30.

Gardner B, Dotan J, Shaikh L, et al (1981). The influence of age upon the survival of adult patients with carcinoma of the colon. Surg Gyn Oncol, 153, 366-8.

Gingras D, Béliveau R (2011). Colorectal cancer prevention through dietary and lifestyle modifications. Cancer Microenviron, 4, 133-9.

Giovannucci E, Ascherio A, Rimm EB, et al (1995). Physical activity, obesity, and risk for colon cancer and adenoma in men. Ann Intern Med, 122, 327-34.

Giovannucci E, Martinez ME (1996). Tobacco, colorectal cancer, and adenomas: A review of the evidence. J Nat Cancer Inst, 88, 1717-30.

Giovannucci E, Rimm EB, Stampfer MJ, et al (1994). Intake 
of fat, meat, and fiber in relation to risk of colon cancer in men. Cancer Res, 54, 2390-7.

Hibi K, Nakao A (2006). Highly-methylated colorectal cancers show poorly-differentiated phenotype. Anticancer Res, $\mathbf{2 6}$, 4263-6.

Jemal A, Bray F, Center MM, et al (2011). Global cancer statistics. CA Cancer J Clin, 61, 69-90.

Kaplan EL, Meier P (1958). Nonparametric estimation from incomplete observations. J Am Stat Assoc, 53, 457-81.

Kim J, Park S, Nam BH (2011). The risk of colorectal cancer is associated with the frequency of meat consumption in a population-based cohort in Korea. Asian Pac J Cancer Prev, 12, 2371-6.

Kune GA, Vitetta L (1992). Alcohol consumption and the etiology of colorectal cancer: a review of the scientific evidence from 1957 to 1991. Nutr Cancer, 18, 97-111.

Lao VV, Grady WM (2011). Epigenetics and colorectal cancer. Nat Rev Gastroenterol Hepatol, 8, 686-700.

MacArthur C, Smith A (1984). Factors associated with speed of diagnosis, referral, and treatment in colorectal cancer. $J$ Epidemiol Community Health, 38, 122-6.

Magalhaes B, Peleteiro B, Lunet N (2012). Dietary patterns and colorectal cancer: Systematic review and meta-analysis. Eur J Cancer Prev, 21, 15-23.

Majumdar SR, Fletcher RH, Evans AT (1999). How does colorectal cancer present? Symptoms, duration, and clues to location. Am J Gastroenterol, 94, 3039-45.

McGaharen ED, Mills SE, Wilhem MC (1995). Colorectal Carcinoma in patients 30 years or younger. Am Surg, 61, 78-82.

Miller FE, Liechty RD (1967). Adenocarcinoma of the colon and rectum in persons under thirty years of age. Am J Surg, 113, 507-10.

Mills SE, Shannon Allen M (1979). Colorectal carcinoma in the first three decades of life. Am J Surg Path, 3, 443-448.

Minardi AJ Jr, Sittig KM, Zibari GB, et al (1998). Colorectal cancer in the young patient. Am Surg, 64, 849-53.

Notani PN (2001). Global variation in cancer incidence and mortality. Current Science, 81, 465-74.

Palmer ML, Herrera L, Petrelli NJ (1991). Colorectal adenocarcinoma in patients less than 40 years of age. Dis Colon Rectum, 34, 343-6.

Rao BN, Pratt CB, Fleming ID, et al (1985). Colon carcinoma in children and adolescents. A review of 30 cases. Cancer, 55, 1322-6.

Recio P, Bussey HJR (1965). The pathology and prognosis of carcinoma of the rectum in the young. Proc $R$ Soc Med, 58, 789-91.

Rodriguez-Bigas MA, Mahoney MC, Weber TK, et al (1996). Colorectal cancer in patients aged 30 years or younger. Surgical Oncol, 5, 189-94.

Seitz HK, Simanowski UA, Garzon FT, et al (1990). Possible role of acetaldehyde in ethanol-related rectal cocarcinogenesis in the rat. Gastroenterol, 98, 406-413.

Sinha R, Hussain S, Mehrotra R, et al (2013). Kras gene mutation and RASSF1A, FHIT and MGMT gene promoter hypermethylation: indicators of tumor staging and metastasis in adenocarcinomatous sporadic colorectal cancer in Indian population. PLoS One, $\mathbf{8 , 6 0 1 4 2 .}$ 